\title{
Health-related quality of life in patients with prostate cancer and their spouses : Results from a longitudinal study
}

\section{Harju, Eeva}

2018-12

Harju , E , Rantanen , A , Helminen, M , Kaunonen, M , Isotalo , T \& Åstedt-Kurki , P 2018 , ' Health-related quality of life in patients with prostate cancer and their spouses : Results from a longitudinal study ' , European Journal of Oncology Nursing , vol. 37 , pp. 51-55 . https://doi.org/10.1016/j.ejo

http://hdl.handle.net/10138/298515

https://doi.org/10.1016/j.ejon.2018.11.001

publishedVersion

Downloaded from Helda, University of Helsinki institutional repository.

This is an electronic reprint of the original article.

This reprint may differ from the original in pagination and typographic detail.

Please cite the original version. 


\title{
Health-related quality of life in patients with prostate cancer and their spouses: Results from a longitudinal study
}

\author{
Eeva Harju $^{\mathrm{a}, *}$, Anja Rantanen ${ }^{\mathrm{a}}$, Mika Helminen ${ }^{\mathrm{b}, \mathrm{c}}$, Marja Kaunonen ${ }^{\mathrm{a}, \mathrm{d}}$, Taina Isotalo ${ }^{\mathrm{e}}$, \\ Päivi Åstedt-Kurki ${ }^{\mathrm{a}, \mathrm{d}}$ \\ ${ }^{a}$ Faculty of Social Sciences, Nursing Science, University of Tampere, Arvo, FI-33014, Finland \\ ${ }^{\mathrm{b}}$ Faculty of Social Sciences, University of Tampere, Arvo, FI-33014, Finland

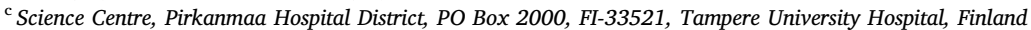 \\ ${ }^{\mathrm{d}}$ Department of General Administration, Pirkanmaa Hospital District, PO Box 2000, FI-33521, Tampere University Hospital, Finland

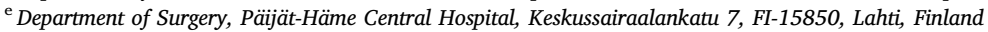

A R T I C L E I N F O

\section{Keywords:}

Longitudinal studies

Prostate cancer

Prostatic neoplasms

Quality of life

Spouses

\begin{abstract}
A B S T R A C T
Purpose: The purpose of this study was to explore changes in HRQoL (health-related quality of life) and identify the associated factors in patients with prostate cancer and their spouses during the year following their diagnosis of prostate cancer.

Methods: The longitudinal study design consisted of 179 patients and 166 spouses, using discretionary sampling, at five Finnish central hospitals. Participants completed a self-reported RAND-36-Item Health Survey at three time-points: time of diagnosis and 6 and 12 months later. Changes in HRQoL were analysed using descriptive statistics and non-parametric tests. Linear mixed-effects models were used to identify the factors associated with the changes in HRQoL in the patients and their spouses.

Results: On average, the HRQoL of patients with prostate cancer changed in physical functioning $(\mathrm{p}=0.015)$, emotional well-being $(\mathrm{p}=0.029)$ and general health $(\mathrm{p}=0.038)$ were statistically significant over the 12 month study period. In spouses, statistically significant changes in HRQoL were not observed. Interaction between the age of participants and changes in HRQoL were statistically significant.

Conclusions: Findings in this study suggest that interventions aimed at improving the HRQoL of patients should support a few different dimensions of HRQoL for the patients themselves than for their spouses. Nurses should pay more attention to elderly couples.
\end{abstract}

\section{Introduction}

A change such as cancer in one family member affects all family members (Wright and Leahey, 2012). Family members experience and react to the changed situation in different ways (Ervik et al., 2013). Spouses of cancer patients react strongly to the patients' illness and treatment, and they experience many difficult problems and increased responsibilities during and after the treatment and rehabilitation phases (Gustavsson-Lilius, 2010; Ervik et al., 2013). Spouses provide the most important psychosocial support for patients with prostate cancer (O'shaughnessy et al., 2015; Forbat et al., 2012). Prostate cancer is the most common type of cancer among men in developed countries as well as in Finnish men (Engholm et al., 2015; Ferlay et al., 2015). All treatment methods for prostate cancer are related to the distinct pattern of changes in quality of life (Harden et al., 2013a; Resnick et al., 2013).

HRQoL is a multidimensional issue and an important patient outcome in oncology. In this study, HRQoL defined emotional, physical, psychological and social and functional domains (Aalto et al., 1999; Ware and Sherbourne, 1992). It has been stated that prostate cancer and its treatment options bring persistent or transient side effects, which affect the patients' as well as the spouses' quality of life (Heidenreich et al., 2011; Harden et al., 2008). Most men experience initial declines in HRQoL in the 2 years after treatment; there is little change from years 3-10, and most differences between treatments attenuated over time (Punnen et al., 2015). In a cohort study among 3294 men, surgery had the largest impact on sexual and urinary functions, radiation had the strongest effect on bowel function, and androgen deprivation therapy had the strongest effect on physical function

\footnotetext{
* Corresponding author.

E-mail addresses: Eeva.J.Harju@uta.fi (E. Harju), Anja.Rantanen@uta.fi (A. Rantanen), Mika.Helminen@uta.fi (M. Helminen), Marja.Kaunonen@uta.fi (M. Kaunonen), Taina.Isotalo@phsotey.fi (T. Isotalo), Paivi.Astedt-Kurki@uta.fi (P. Åstedt-Kurki).
} 
(Punnen et al., 2015). In a prospective, population-based cohort study (Barocas et al., 2017), radical prostatectomy (RP) was associated with significant declines in sexual function compared with external beam radiation therapy (EBRT) and active surveillance. According to the data from a Japanese longitudinal study of 750 patients who underwent an RP or EBRT treatment method, the pattern in the changes over time of the HRQoL domains differed between the two treatment groups (Namiki et al., 2011). The RP group reported an improvement with regard to role limitations due to physical and emotional problems after an initial decline at 3 months and had values similar to the baseline at 24 months (Namiki et al., 2011). The EBRT group did not show improvements over the baseline values (Namiki et al., 2011). Compared to patients being managed on active surveillance (AS) and EBRT, EBRT patients reported significantly worse bowel function during the 3-year follow-up period (Banerji et al., 2017). In addition, other diseases could affect the HRQoL of prostate cancer patients. Patients' and their spouses' appraisals of the prostate cancer and their dyadic communication were associated with their long-term QoL (Song et al., 2016). Ross and colleagues (2016) examined that not only patients but also their spouses experience a significant decrease in mental and physical health 1 month post surgery.

Associations between socioeconomic status (SES) and HRQoL among patients with prostate cancer are identified in a German longitudinal prospective cohort study (Klein et al., 2016). Lower SES as income, education and employment status was significantly associated with lower HRQoL 6 months after radical prostatectomy treatment (Klein et al., 2016). A previous study has shown that prostate cancer survivors with comorbid diabetes have poorer cancer-specific and general HRQoL than those without diabetes (Thong et al., 2011).

Several studies have identified the associations between treatment methods and the HRQoL of patients with prostate cancer or their spouses (Vasarainen et al., 2013; Harden et al., 2013b). Although, there is some knowledge about HRQoL in patients with prostate cancer, a simultaneous follow-up on the HRQoL of these patients and their spouses is worth investigating further.

\section{Aims}

The aim of this study was to explore changes in HRQoL and identify the associated factors in patients with prostate cancer and their spouses during the year following their diagnosis of prostate cancer. The research questions were:

1. How does the HRQoL of patients with prostate cancer and their spouses change during the year following their diagnosis of prostate cancer?

2. Which factors are associated with changes in the HRQoL of patients with prostate cancer and their spouses during the 1-year follow-up period?

\section{Methods}

\subsection{Sample, study design and participants}

The data for this longitudinal study consisted of patients with prostate cancer $(\mathrm{N}=350)$ and their spouses $(\mathrm{N}=350)$, using discretionary sampling at the time of diagnosis and during the 1-year period that followed. The study design was approved by the Scientific Committee of the local hospital district. The directors of the 5 participating hospitals permitted its execution. Each participant was informed orally and in writing about the purpose of the study and of the principle of voluntary, anonymous participation.

The sample size was based on previous studies (OSOBA et al., 2005) and was calculated together with a statistician. A clinically significant change in HRQoL scores was determined on a 10-point scale. The sample size calculation was based on a paired-samples $t$-test. Using a standard deviation of 20 with an alpha value of 0.05 and a power of 0.8 , a change of 10 points was calculated to be statistically significant with a sample of 33 participants (OSOBA et al., 2005). Because there were 3 points of measurement, 5 different hospitals and at least 4 types of treatment, the questionnaire was distributed to 350 couples at the first measurement point.

In the first stage of this study, the participants were recruited between October 2013 and January 2016 from the outpatient urology clinics of five Finnish central hospitals. The inclusion criteria were (i) patients examined with prostate cancer who were at the pre-treatment stage, (ii) patients that characterised their relationship with their spouse as permanent, and (iii) patients who provided written informed consent and additional contact information for their spouses.

At the 6-month post-diagnosis data collection point, there were 199 of 231 (86\%) patients with prostate cancer and 195 of 228 (86\%) spouses. The questionnaires were sent to patients or spouses who had answered the questionnaire at the time of diagnosis and were willing to continue with the study. At the second stage, data collection was carried out between April 2014 and July 2016.

At the third stage, 1-year post diagnosis, the response rate was $90 \%$ $(n=179)$ for the patients and $85 \%(n=166)$ for the spouses. The main analyses employed all participants with available data at each of the 3 time-points (patients $n=179$, spouses $n=166$ ).

During the period under investigation, the patients had four different treatment method options: Surgery (all forms of radical prostatectomy), radiation therapy (brachytherapy and external beam radiation), hormonal treatment, and non-invasive care (active and passive follow-up care). Treatment protocols for prostate cancer did not differ between the five hospitals, but nursing appointments did vary between the hospitals.

\subsection{Data collection methods}

General HRQoL was assessed using the RAND-36-item health survey (RAND-36), which included 8 health dimensions: physical functioning, role functioning/physical, role functioning/emotional, energy, emotional well-being, social functioning, bodily pain and general health (Aalto et al., 1999; Ware and Sherbourne, 1992). The RAND-36 is a widely used measure of generic HRQoL. The subscales were linearly converted to a $0-100$ scale according to standard scoring procedures, with higher scores indicating a better HRQoL (Aalto et al., 1999). For the RAND-36, differences of $\geq 10$ points were considered clinically meaningful (OSOBA et al., 2005). The RAND-36 has been validated for the Finnish population (Aalto et al., 1999).

The demographic variables included age, duration of the marital relationship, education status, employment status, other diseases, place of treatment and treatment methods.

\subsection{Data analysis}

Data were described using frequencies, percentages, means and standard deviations. Changes between the time of diagnosis and 1 year after diagnosis were analysed using the Wilcoxon signed-rank test due to skewed distributions. Calculations were performed using the IBM SPSS statistics Version 23 (IBM Corp., Armonk, NY, USA) and R version 3.3.0. Linear mixed-effects models using the function 'lme' were assessed for all eight health dimensions separately for prostate cancer patients and their spouses. Age, duration of the marital relationship, education status, employment status, other diseases, place of treatment and treatment methods were used as independent variables, together with time-variable (three time points), with patient models. For spouses' models, place of treatment and treatment methods were not used. A random intercept for individuals with a random slope for individual time variations were used together with independent random errors. The level of statistical significance was set at $\mathrm{p}<0.05$ (Munro, 2005). 
Table 1

Demographic characteristics of patients with prostate cancer $(n=179)$ and their spouses $(n=166)$ one year after diagnosis.

\begin{tabular}{|c|c|c|c|c|}
\hline \multirow[t]{2}{*}{ Variable } & \multicolumn{2}{|l|}{ Patients } & \multicolumn{2}{|c|}{ Spouses } \\
\hline & $n$ & $\%$ & $n$ & $\%$ \\
\hline \multicolumn{5}{|l|}{ One-year follow-up } \\
\hline Age (years) & $67.9(9.8)^{\mathrm{a}}$ & & $65.6(8.7)^{\mathrm{a}}$ & \\
\hline$\leq 59$ & 30 & 17 & 40 & 24 \\
\hline $60-69$ & 70 & 39 & 68 & 41 \\
\hline$\geq 70$ & 79 & 44 & 58 & 35 \\
\hline Duration of marital relationship (years) & $36.0(15.6)^{\mathrm{a}}$ & & & \\
\hline$\leq 25$ & 48 & 27 & & \\
\hline $26-40$ & 43 & 24 & & \\
\hline$\geq 41$ & 88 & 49 & & \\
\hline \multicolumn{5}{|l|}{ Basic education } \\
\hline Elementary school/civic school & 101 & 56 & 72 & 43 \\
\hline $\begin{array}{l}\text { Comprehensive school/lower secondary } \\
\text { school }\end{array}$ & 48 & 27 & 45 & 27 \\
\hline Upper secondary school & 30 & 17 & 49 & 30 \\
\hline \multicolumn{5}{|l|}{ Employment status } \\
\hline Working & 57 & 32 & 67 & 40 \\
\hline Not working & 122 & 68 & 99 & 60 \\
\hline \multicolumn{5}{|l|}{ Chronic diseases } \\
\hline Yes & 127 & 71 & 106 & 64 \\
\hline No & 51 & 29 & 60 & 36 \\
\hline Missing & 1 & & & \\
\hline \multicolumn{5}{|l|}{ Treatment method } \\
\hline Radiation therapy & 65 & 37 & & \\
\hline Surgery & 63 & 35 & & \\
\hline Non-invasive care & 32 & 18 & & \\
\hline Hormonal treatment & 18 & 10 & & \\
\hline Missing & 1 & & & \\
\hline
\end{tabular}

a $=$ mean (standard deviation).

\section{Results}

\subsection{Demographic characteristics of participants}

Responses were received from 179 (51\%) patients and 166 (47\%) spouses 1 year after diagnosis. The mean age of the patients was 68 years (9.78) and of the spouses 66 years (8.67). The demographic characteristics of participants are presented in Table 1.

\subsection{HRQoL during the 1-year follow-up}

Table 2 summarises HRQoL during the year following prostate cancer diagnosis. On average, the HRQoL of the patients with prostate cancer change in physical functioning, emotional well-being and general health was statistically significant over the 12-month study period. The mean of physical functioning of the patients was M 81.0 (SD 21.4) at the time of diagnosis and M 79.2 (SD 21.1) 12 months after. The difference was statistically significant $(\mathrm{p}=0.015)$. For emotional wellbeing, the change went from M 75.6 (SD 16.3) to M 78.9 (SD 15.7) ( $p=0.029$ ), and for general health, it went from M 58.7 (Sd 17.8) to M 58.3 (SD 21.1). In patients, there were no other statistically significant changes. In spouses, statistically significant changes in HRQoL were not observed. In addition, Table 2 includes data for participants for whom the HRQoL changed by 10 points or more on the RAND-36 scale. Patients' and spouses' changes were very similar.

\subsection{Factors associated with change in HRQoL}

Linear mixed-effects models were used to explore the demographic variables regarding 8 dimensions of HRQoL. HRQoL was a dependent variable and the demographic variables together with time were independent variables.

Linear mixed-effects modelling showed that changes in the HRQoL of participants were minor over the 12-month study period. Clinically

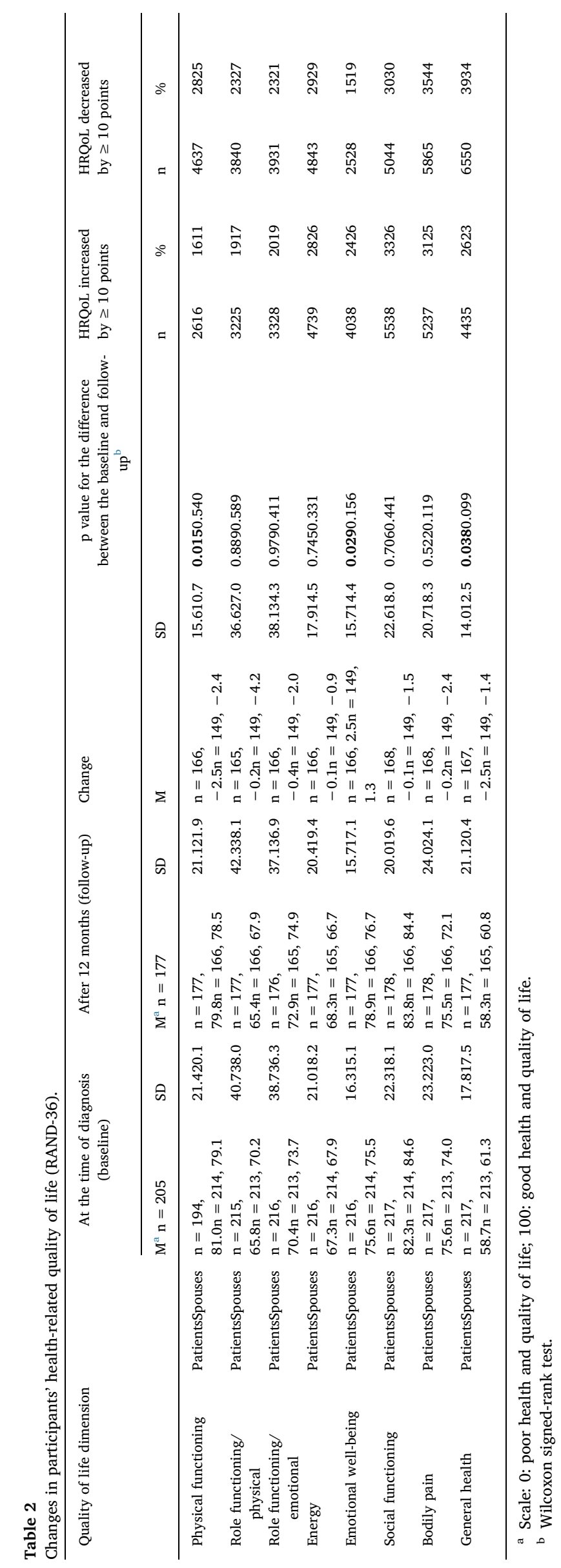


significant changes in HRQoL were not observed. On average, general health decreased 2 points on the RAND-36 scale.

The effect of demographic variables was insignificant. Twelve months after prostate cancer was diagnosed, the demographic variables did not significantly explain the variance of the participants' HRQoL. Only the interaction between the participants' ages and changes in their HRQoL was statistically significant in some of the models. The HRQoL of participants over the age of 70 decreased more than in the younger participants.

\section{Discussion}

This study reported changes in the HRQoL of patients with prostate cancer and their spouses at the 1-year follow-up period. The main findings were that the HRQoL of the patients and their spouses changed during the follow-up period. Physical functioning and general health of patients decreased, and emotional well-being of patients increased. Similar changes were not observed in spouses, as they did not have statistically significant changes in HRQoL dimensions.

These findings support the previous studies, which concluded that patients with locally advanced or advanced prostate cancer reported decrements, especially in physical quality of life at 2, 6, 12, 24 and 48 months after their diagnoses (Zajdlewicz et al., 2017), and the QoL of spouses was generally good based on a generic QoL instrument in a longitudinal 2-year follow-up study (Harden et al., 2013a). Similarly, another longitudinal study of men with advanced prostate cancer reported that HRQoL fluctuates from the time of diagnosis to 5 years after, but a substantial proportion of the men remained distressed (Zajdlewicz et al., 2017). According to Paterson et al. (2015), a significant decline in quality of life was observed at 6 months post diagnosis when they used a prostate cancer-specific measurement. Correspondingly, most men experience initial declines in HRQoL in the 2 years following their treatment; there is little change in years 3-10, and most differences between treatments attenuated over time (Punnen et al., 2015). On the other hand, a Spanish study in patients with lung, head, neck, colorectal, or breast cancer reported that after 3 months of usual care, there was a significant improvement in pain and the quality of life (Maximiano et al., 2018). Our findings show that clinically significant changes in HRQoL were not found in this study. Our results add important knowledge about understanding the family dynamics of men with prostate cancer.

A surprising finding in this study was that the emotional well-being of patients increased during the follow-up period. This could be because after the prostate cancer diagnosis, patients are able to better share their concerns with their spouses or healthcare professionals when their emotional well-being has increased. According to Ernstmann et al. (2017), patient-provider communication is a valuable resource to support patients with prostate cancer. This study thus supports the recommendations of Ernstmann et al. (2017) that interventions, especially for urologists, enhance their awareness about the importance of communication and their relationships with their patients for treatment outcomes. On the other hand, previous studies (Gustavsson-Lilius, 2010; Lim et al., 2015) showed that male patients with cancer tended not to talk about their negative symptoms with their spouses.

Our discovery regarding the ages of patients and their spouses and how they affect changes in general health are in agreement with previous studies (Song et al., 2011; Harrington et al., 2013) and suggest potential intervention targets. Prior study suggests nurses pay more attention to couples older than 70 years who have other chronic disease or who receive hormonal treatment (Harju et al., 2017). Otherwise, previous studies have shown that a younger age was associated with a poorer QoL (Harden et al., 2008; Wu and Harden, 2015). However, it should be noted that in our study, the interaction of demographic variables with the changes of HRQoL was not found. One explanation for this could be that the follow-up period is too short. However, the longitudinal study is to our advantage. The strength of this study is that the data are longitudinally and simultaneously collected from the same patients with prostate cancer and their spouses.

\subsection{Limitations}

This study has several limitations, which should be noted when considering the findings. First, this study focused on patients with prostate cancer who live in a marital relationship. Second, the use of only one scale of HRQoL (RAND-36) could simplify the complex concept of QoL. Third, there may have been selection bias in the data collection. The respondents who were willing to participate in this study were mostly likely those who were healthy. Furthermore, some respondents may have overemphasised their poor health to elicit sympathy. Last, self-reported data on early disease and treatment methods are limited by the patients' understanding and recall of treatments. To improve reliability, information on chronic diseases and the progression of prostate cancer could be collected from medical records. Confounders, such as support groups, or family relationships, or economic factors, may also have influenced the results.

In conclusion, 1 year after prostate cancer diagnosis, changes in physical functioning, emotional well-being and general health are common in patients, but not in spouses. The only significant factor for changes in one dimension of HRQoL was age. To improve HRQoL in patients with prostate cancer, this study highlights the need to target support for the physical functioning of patients and older couples.

\section{Acknowledgements}

This study was supported by grants from the School of Health Sciences (University of Tampere), the Finnish Association of Urological Nurses, the Finnish Foundation of Urological Research and the Nursing Foundation of the Pirkanmaa Hospital District.

\section{References}

Aalto, A., Aro, A.R., Teperi, J., 1999. RAND-36 as a Measure of Health-related Quality of Life. Reliabilty, Construct Validy and Reference Values in the Finnish General Population. Stakes, Helsinki Research Reports 101.

Banerji, J.S., Hurwitz, L.M., Cullen, J., Wolff, E.M., Levie, K.E., Rosner, I.L., Brand, T.C., L'esperance, J.,O., Sterbis, J.R., Porter, C.R., 2017. A prospective study of healthrelated quality-of-life outcomes for patients with low-risk prostate cancer managed by active surveillance or radiation therapy. Urol. Oncol. 35 (5), 234-242.

Barocas, D.A., Alvarez, J., Resnick, M.J., Koyama, T., Hoffman, K.E., Tyson, M.D., Conwill, R., Mccollum, D., Cooperberg, M.R., Goodman, M., Greenfield, S., Hamilton, A.S., Hashibe, M., Kaplan, S.H., Paddock, L.E., Stroup, A.M., Wu, X., Penson, D.F. 2017. Association between radiation therapy, surgery, or observation for localized prostate cancer and patient-reported outcomes after 3 years. J. Am. Med. Assoc. 317 (11), 1126-1140.

Engholm, G., Ferlay, J., Christensen, N., Johannesen, T.B., Khan, S., Køtlum, J.E., Et Al, N., 2015. Last Update, Cancer Incidence, Mortality, Prevalence and Survival in the Nordic Countries. Association of Nordic Cancer Registries. Danish Cancer Society Version 7.2(12/2015). http://www.ancr.nu/ancr/2016.

Ernstmann, N., Weissbach, L., Herden, J., Winter, N., Ansmann, L., 2017. Patient-physician communication and health-related quality of life of patients with localised prostate cancer undergoing radical prostatectomy - a longitudinal multilevel analysis. BJU Int. 119 (3), 396-405.

Ervik, B., Nordoy, T., Asplund, K., 2013. In the middle and on the sideline: the experience of spouses of men with prostate cancer. Cancer Nurs. 36 (3), E14.

Ferlay, J., Soerjomataram, I., Ervik, M., Dikshit, R., Eser, S., Mathers, C., Rebelo, M., Parkin, D.M., Forman, D., Bray, F., 2015. Last Update, GLOBOCAN 2012 v1.0, Cancer Incidence and Mortality Worldwide: IARC CancerBase No. 11 [Internet]. International Agency for Research on Cancer, Lyon, France 2013. [8/, 2015].

Forbat, L., White, I., Marshall-Lucette, S., Kelly, D., 2012. Discussing the sexual consequences of treatment in radiotherapy and urology consultations with couples affected by prostate cancer. BJU Int. 109 (1), 98-103.

Gustavsson-Lilius, M., 2010. Psychological Consequences of Cancer from the Salutogenic and Dyadic Perspective. University of Helsinki, Helsinki.

Harden, J., Sanda, M., Wei, J., Yarandi, H., Hembroff, L., Hardy, J., Northouse, L., Prostqa Consortium Study Group., 2013. Partners' long-term appraisal of their caregiving experience, marital satisfaction, sexual satisfaction, and quality of life 2 years after prostate cancer treatment. Cancer Nurs. 36 (2), 104-113.

Harden, J., Sanda, M.,G., Wei, J.,T., Yarandi, H.,N., Hembroff, L., Hardy, J., Northouse, L., 2013b. Survivorship after prostate cancer treatment: spouses' quality of life at 36 months. Oncol. Nurs. Forum 40 (6), 567-573.

Harden, J., Northouse, L., Cimprich, B., Pohl, J.M., Liang, J., Kershaw, T., 2008. The 
influence of developmental life stage on quality of life in survivors of prostate cancer and their partners. J. Cancer Surviv. 2 (2), 84-94.

Harju, E., Rantanen, A., Kaunonen, M., Helminen, M., Isotalo, T., Åstedt-Kurki, P., 2017. The health-related quality of life of patients with prostate cancer and their spouses before treatment compared with the general population. Int. J. Nurs. Pract. 23 (5), 1-9.

Harrington, J.M., Schwenke, D.C., Epstein, D.R., 2013. Exercise preferences among men with prostate cancer receiving androgen-deprivation therapy. Oncol. Nurs. Forum 40 (5), E367.

Heidenreich, A., Bellmunt, J., Bolla, M., Joniau, S., Mason, M., Matveev, V., Mottet, N., Schmid, H., Van Der Kwast, T., Wiegel, T., Zattoni, F., 2011. EAU guidelines on prostate cancer. Part 1: screening, diagnosis, and treatment of clinically localised disease. Eur. Urol. 59 (1), 61-71.

Klein, J., Hofreuter-Gätgens, K., Lüdecke, D., Fisch, M., Graefen, M., Von, D.K., 2016. Socioeconomic status and health-related quality of life among patients with prostate cancer 6 months after radical prostatectomy: a longitudinal analysis. BMJ Open 6 (6), e010968.

Lim, J., Paek, M., Shon, E., 2015. Gender and role differences in couples' communication during cancer survivorship. Cancer Nurs. 38 (3), E51 - E60.

Maximiano, C., Lopez, I., Martin, C., Zugazabeitia, L., Marti-Ciriquian, J.L., Nunez, M.A., Contreras, J., Herdman, M., Traseira, S., Provencio, M., 2018. An exploratory, largescale study of pain and quality of life outcomes in cancer patients with moderate or severe pain, and variables predicting improvement. PloS One 13 (4), e0193233.

Munro, B.H., 2005. Statistical Methods for Health Care Research, 5. ed. edn. Lippincott Williams \& Wilkins, Philadelphia (Pa.).

Namiki, S., Tochigi, T., Ishidoya, S., Ito, A., Numata, I., Arai, Y., 2011. Long-term quality of life following primary treatment in men with clinical stage T3 prostate cancer. Qual. Life Res. 20 (1), 111-118.

O'shaughnessy, P.,K., Laws, T.,A., Esterman, A.J., 2015. The prostate cancer journey: results of an online survey of men and their partners. Cancer Nurs. 38 (1), E12.

OSOBA, D., BEZJAK, A., BRUNDAGE, M., ZEE, B., TU, D., PATER, J., Quality of Life Committee of the, NCIC CTG, 2005. Analysis and interpretation of health-related quality-of-life data from clinical trials: basic approach of the National Cancer Institute of Canada Clinical Trials Group. Eur. J. Canc. 41 (2), 280-287.

Paterson, C., Robertson, A., Nabi, G., 2015. Exploring prostate cancer survivors' selfmanagement behaviours and examining the mechanism effect that links coping and social support to health-related quality of life, anxiety and depression: a prospective longitudinal study. Eur. J. Oncol. Nurs. 19 (2), 120-128.

Punnen, S., Cowan, J.E., Chan, J.M., Carroll, P.R., Cooperberg, M.R., 2015. Long-term health-related quality of life after primary treatment for localized prostate cancer: results from the CaPSURE registry. Eur. Urol. 68 (4), 600-608.

Resnick, M.J., Koyama, T., Fan, K., Albertsen, P.C., Goodman, M., Hamilton, A.S., Hoffman, R.M., Potosky, A.L., Stanford, J.L., Stroup, A.M., Van Horn, R.L., Penson, D.F., 2013. Long-term functional outcomes after treatment for localized prostate cancer. N. Engl. J. Med. 368 (5), 436-445.

Ross, K.M., Ranby, K.W., Wooldridge, J.S., Robertson, C., Lipkus, I.M., 2016. Effects of physical and mental health on relationship satisfaction: a dyadic, longitudinal examination of couples facing prostate cancer. Psycho Oncol. 25 (8), 898-904.

Song, L., Northouse, L., Braun, T., Zhang, L., Cimprich, B., Ronis, D., Mood, D., 2011. Assessing longitudinal quality of life in prostate cancer patients and their spouses: a multilevel modeling approach. Qual. Life Res. 20 (3), 371-381.

Song, L., Rini, C., Ellis, K.R., Northouse, L.L., 2016. Appraisals, perceived dyadic communication, and quality of life over time among couples coping with prostate cancer. Support. Care Canc. 24 (9), 3757-3765.

Thong, M.S.Y., Van De Poll-Franse, L.V., Hoffman, R.M., Albertsen, P.C., Hamilton, A.S., Stanford, J.L., Penson, D.F., 2011. Diabetes mellitus and health-related quality of life in prostate cancer: 5-year results from the Prostate Cancer Outcomes Study. BJU Int. 107 (8), 1223-1231.

Vasarainen, H., Malmi, H., Maattanen, L., Ruutu, M., Tammela, T., Taari, K., Rannikko, A., Auvinen, A., 2013. Effects of prostate cancer screening on health-related quality of life: results of the Finnish arm of the European randomized screening trial (ERSPC). Acta Oncol. (Stockh.) 52 (8), 1615-1621.

Ware, J.E.J., Sherbourne, C.D., 1992. The MOS 36-ltem short-form health survey (SF-36): I. Conceptual framework and item selection. Med. Care 30 (6), 473-483.

Wright, L.M., Leahey, M., 2012. Nurses and Families: a Guide to Family Assessment and Intervention, sixth ed. F.A. Davis Company, Philadelphia.

Wu, H., Harden, J.K., 2015. Symptom burden and quality of life in survivorship: a review of the literature. Cancer Nurs. 38 (1), 29.

Zajdlewicz, L., Hyde, M.K., Lepore, S.J., Gardiner, R.A., Chambers, S.K., 2017. Healthrelated quality of life after the diagnosis of locally advanced or advanced prostate cancer: a longitudinal study. Cancer Nurs. 40 (5), 412-419. 